\title{
ENVIRONMENTAL ASSESSMENT METHOD FOR A SMALL-RIVER RESTORATION PLAN
}

\author{
R. LOPA \& Y. SHIMATANI \\ Department of Urban and Environmental Engineering, Kyushu University, Japan.
}

\begin{abstract}
Although more than 23,000 river restoration projects have been conducted during the past 15 years in Japan, reliable environmental assessment methods have not yet been identified. The environment of the Kamisaigo River is assessed before restoration. The river had been canalized with concrete revetments, reducing its biological function. In 2007, the Fukutsu City Government initiated a program to restore the environmental quality of the river. The aim of this paper was to determine the best method of assessing the river environment. The fish and the physical environment to assess the environmental condition of the river are surveyed. A fish index developed by Kyushu University adequately represented characteristics of river health and was used to determine which sites warranted restoration, rehabilitation priorities, and appropriate methods. The authors calculated 14 regionally developed indices using the ecological features of the fish at several river sites. The environmental quality of the river varied substantially across seven sampling sites. Using these assessment results, the authors determined the specific weaknesses that affected the condition of each site. A restoration and improvement program based on these findings accomplished several goals, including restoring the floodplain, incorporating a variety of flow rates, and enhancing vegetation for fish spawning.

Keywords: Assessment methods, environmental condition, fish index, rehabilitation plan, river restoration.
\end{abstract}

\section{INTRODUCTION}

Various efforts are being made to conserve habitats of small-scale rivers. In recent years, river improvement works and basin developments have reduced and fragmented habitats in floodplains, such as backwaters, creeks, and wetlands. To restore these deteriorated elements, groynes, wildlifecompatible revetments, backwaters, and wetlands have been built and fishways have been constructed in many rivers [1].

In 1990, the Japanese Ministry of Construction created the naturally diverse river improvements or river restoration projects. More than 23,000 projects have so far been conducted. The conservation and restoration of river environments requires targets, yet reliable environmental assessment methods have not yet been identified. We assessed the environment of the Kamisaigo River before restoration in order to focus on areas where substantial benefits to the river ecology and management could be achieved. We used fish as indicators. Fish are essential to the successful functioning of a river ecosystem; thus, any changes that reduce the population size, the community composition, or the availability of prey will affect all facets of a river's ecology. Fish are excellent indicators of catchment health because (1) they spend their entire lifecycle in water, (2) they differ in tolerance to amounts and types of pollution, (3) they are easy to collect, (4) they are relatively long lived, and (5) they are easy to identify in the field [2].

Biological integrity is 'the ability to support and maintain a balanced, integrated adaptive assemblage of organisms having species composition, diversity, and functional organization comparable to that of the natural habitat of the region' [3]. An index of biological health combines diverse biological information to numerically depict associations between human influences and biological attributes. An index is composed of several biological attributes or metrics that are sensitive to changes in biological integrity caused by human activities. This multiple-metric 
approach compares what is found at a monitoring site with what is expected under a regional baseline condition that reflects little or no human impact [3]. Consequently, ecosystem health is determined by the conditions in which 'the organisms that should be around in that ecosystem can properly survive' [4].

The micro-topography of a river is formed through the interaction between flowing water, sediment, plants, structures, river form, water flow, and bank geography and provides a variety of habitats for different organisms and for organisms at different stages of their lifecycles. Shallows, pools, and loose stone stripes are all typical habitats in water. The most important characteristic of a river habitat is that it can be lost and reproduced repeatedly. This means that habitats are always changing.

Fish habitats can be classified by their flow characteristics into rapids, riffles, runs, glides, slacks, shallows, and scour pools.

Preserving an ecologically sound environment involves the maintenance of the diversity and productivity of aquatic species; thus, research must continually refine habitat assessment methods. The objectives of this paper were to determine the best method for assessing a river environment and to evaluate river health on the basis of a fish ecological health index. We present a new concept for handling the preliminary assessment of a river environment. Our results will contribute to the development of rehabilitation plans and will enhance conservation efforts.

\section{STUDY AREA}

The second-order Kamisaigo River, in Fukutsu, Fukuoka Prefecture, Japan (33 $45^{\prime} 24.29^{\prime \prime}$ to $33^{\circ} 45^{\prime} 40.16^{\prime \prime} \mathrm{N}, 130^{\circ} 29^{\prime} 55.52^{\prime \prime}$ to $130^{\circ} 29^{\prime} 25.15^{\prime \prime E}$; Fig. 1) has a water surface width of 2.4 to 6.8 $\mathrm{m}$ and depths ranging from 11 to $30 \mathrm{~cm}$. The study area was an $800-\mathrm{m}$ reach located at the confluence with the Saigo River. The primary use of this river is irrigation, and the majority of surrounding land is dedicated to residential and commercial uses. The river has been canalized and lined with concrete; this action has damaged the physical and biological functions of the river.

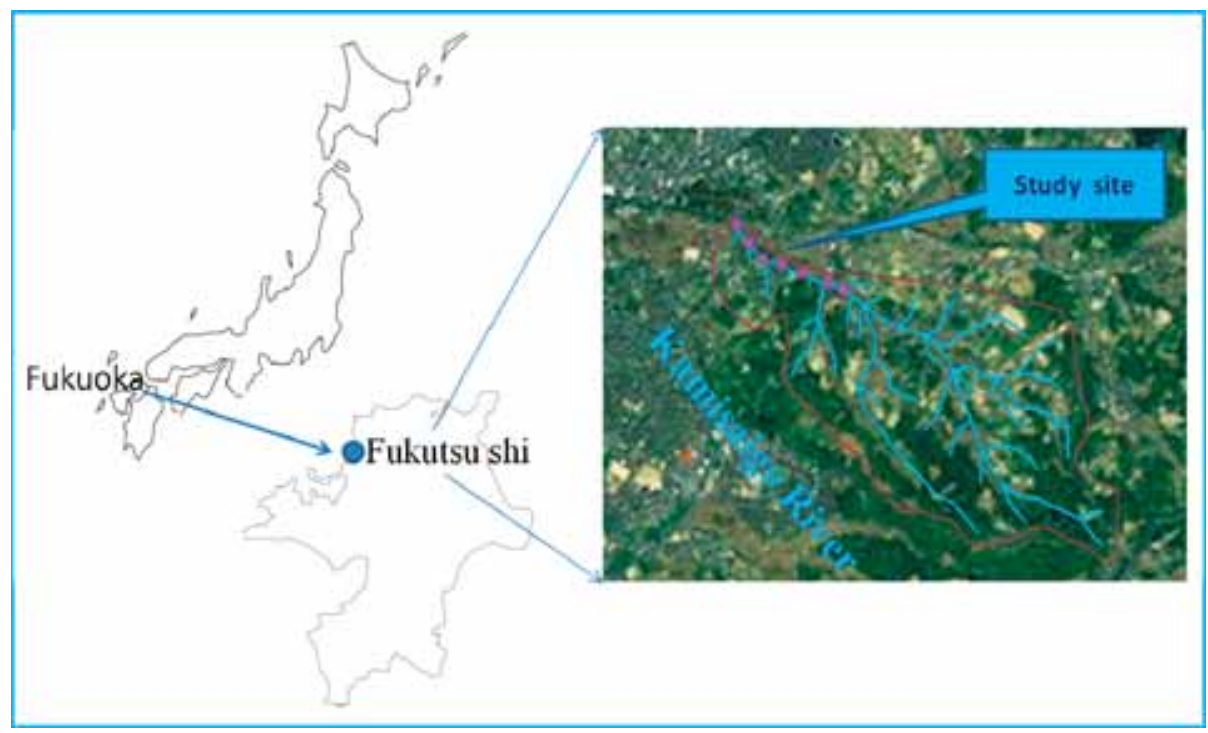

Figure 1: Study site: Kamisaigo River, Fukuoka, Japan. 
In addition, the river is flood prone, and the overall environment has become inhospitable for aquatic life. The river does not attract recreational activities and thus remains disconnected from the community.

In 2007, the Fukutsu City Government initiated a program to restore the environmental quality of the river. The program intends to create a more aesthetic, natural river habitat, to improve the general environment for aquatic organisms, and to foster a strong connection between the local community and the river environment.

\section{METHODS}

\subsection{Fish sampling}

In the autumn (October-November) of 2009, we conducted a fish survey along the 800-m reach using a backpack electro-fisher (LR-24 Smith-Root, Vancouver, WA, USA). Seven 50-m stretches were each blocked with seine netting to enclose populations. The fish that were caught were measured (total number of fish, length, weight) and released alive (Fig. 2).

\subsection{Flow ecological mapping in the Kamisaigo River}

We drew habitat maps of the river showing rapid riffles, runs, glides, slack shallows, and scour pools. We recorded the number of pools, glides, riffles, and rapids at each station and took photographs (Fig. 3).

\subsection{Data collection and analysis}

To evaluate the health of the fish assemblage in the river, we calculated values of 14 fish metrics: (1) native species, (2) endangered species, (3) freshwater species, (4) diadromous species, (5) swimming species, (6) bottom-dwelling species, (7) species that live usually in flow areas, (8) species that live usually in calm areas, (9) mainstream species, (10) floodplain species, (11) species that spawn in aquatic vegetation, (12) species that spawn on muddy bottoms, (13) species that spawn on gravel bottoms, and (14) species that spawn on rocky bottoms. These metrics are typically evaluated with

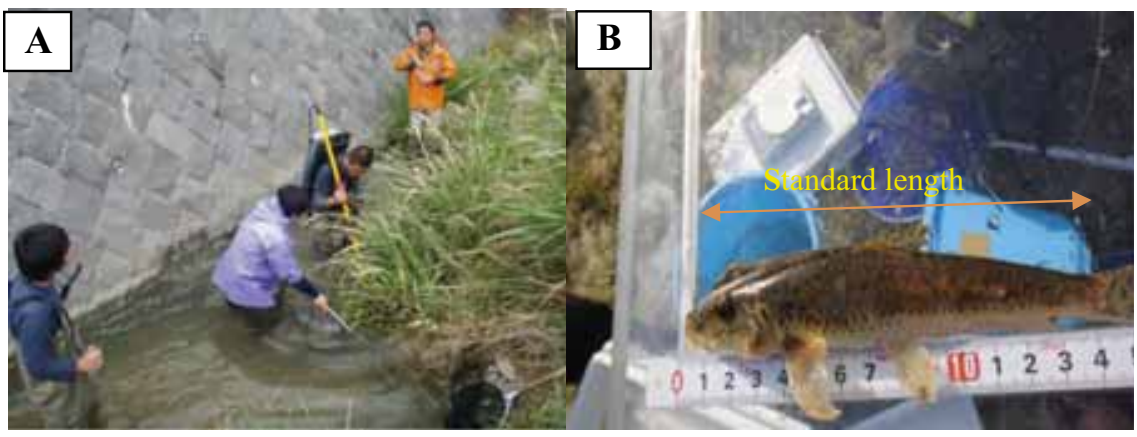

Figure 2: Fish sampling. (A) netting fish after they had been shocked; (B) weighing and measuring the length of fish. 


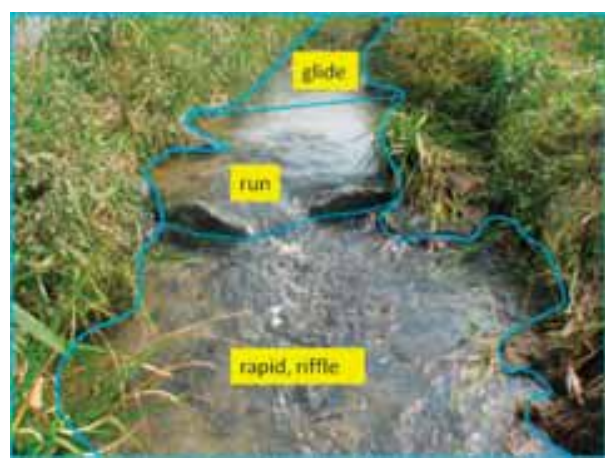

Figure 3: Flow ecological mapping.

respect to criteria such as the environmental significance of the site and data availability. The fish species are listed and scored against criteria developed from high-quality historical data. To verify sampling efficacy, we compared our species list with lists developed by Kyushu University and, where available, those from previous fish collections.

An index based on the 14 metrics, developed by Kyushu University [5], was used to compare the conditions of the sampling stations. We calculated the Fish Biological Health Index (FBHI) as

$$
\mathrm{FBHI}_{i j}=10 \times N_{\mathrm{kij}} / N_{\mathrm{s} j}
$$

where $i$ is station number (1-7), $j$ is metric number (1-14), $N_{\mathrm{kij}}$ is the number of species in metric $j$ at station $i$, and $N_{\mathrm{sj}}$ is the number of species in metric $j$ at all stations combined.

The FBHI scores represent characteristics of river health and can be used to determine which rivers (or segments) warrant restoration, and the appropriate methods. The overall FBHI was calculated in three steps: (1) each $\mathrm{FBHI}_{i j}$ was calculated, (2) the mean of each metric was calculated $\left(\frac{\sum_{k=1}^{7} \mathrm{FBII}_{k j}}{7}\right)$, and (3) the $\mathrm{FBHI}_{j}$ of each metric was averaged to give the $\mathrm{FBHI}_{i j}$ of each station.

\section{RESULTS AND DISCUSSION}

We collected 746 fishes of 15 species from the Kamisaigo River (Table 1).

The fish metrics assess the species richness component of diversity and the health of resident taxonomic groupings and habitat guilds of fishes (Tables 2, 3).

Metric 1. Origin of the fish community (native species). Substitutes (Table 2).

Metric 2. Endangered species. Substitutes (Table 2).

Metrics 3 and 4. Life history type (freshwater and diadromous, respectively). Substitutes (Table 2). Metrics 5 and 6. Swimming layer (upper- and bottom-dwelling, respectively). Substitutes (Table 2).

Metrics 7 and 8. Suitable current type (flow areas and calm areas, respectively). Substitutes (Table 2).

Metrics 9 and 10. Habitat type (mainstream and floodplain, respectively). Substitutes (Table 2).

Metrics 11-14. Spawning ecology type (vegetation, muddy bottoms, gravel bottoms, and rocky bottoms, respectively). Substitutes (Table 2).

The composition of flow ecology in the Kamisaigo River (Fig. 4) allowed us to define the characteristics of the river's natural environment. From the calculations in Table 4, we graphed the results (Fig. 5). 


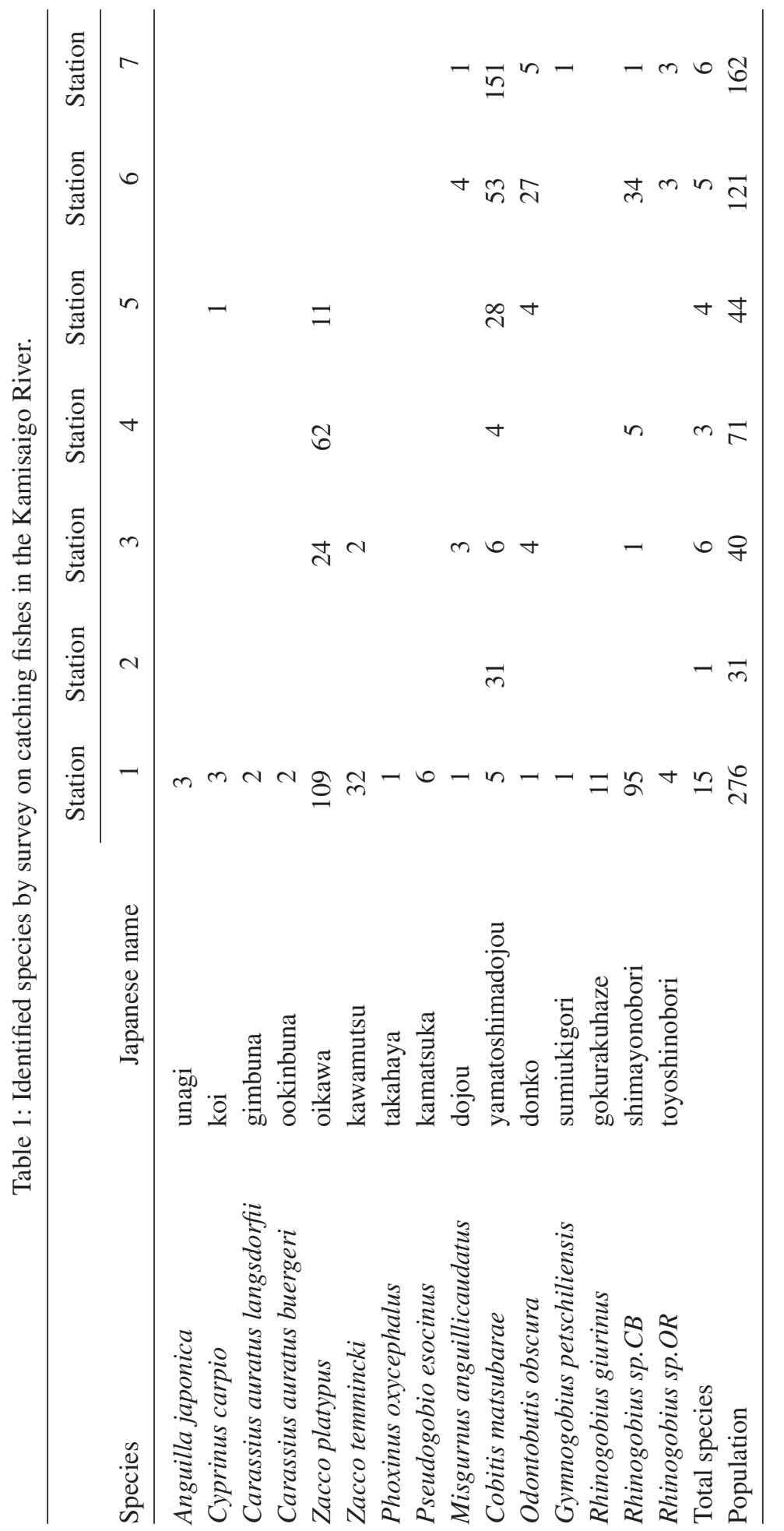




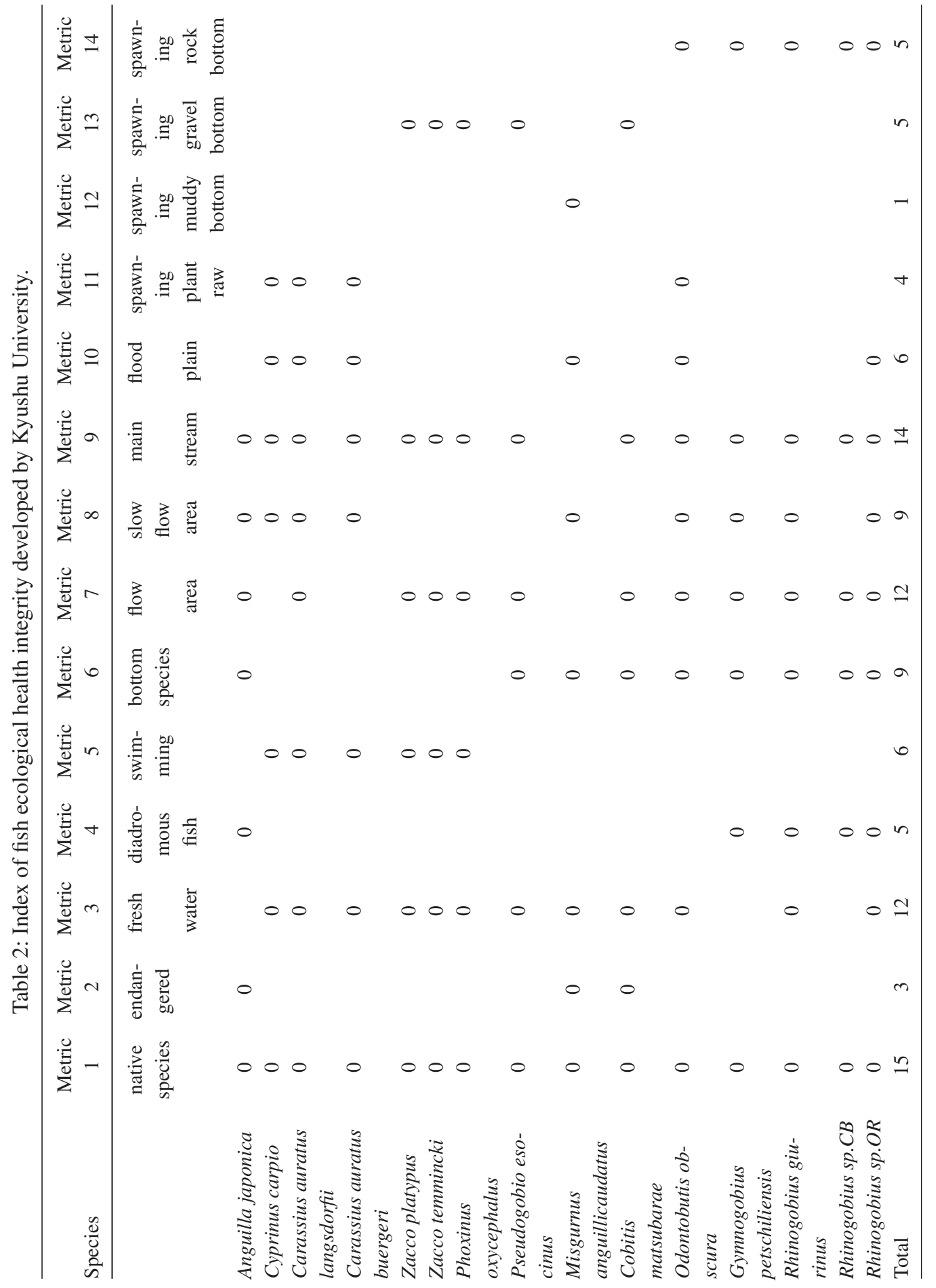




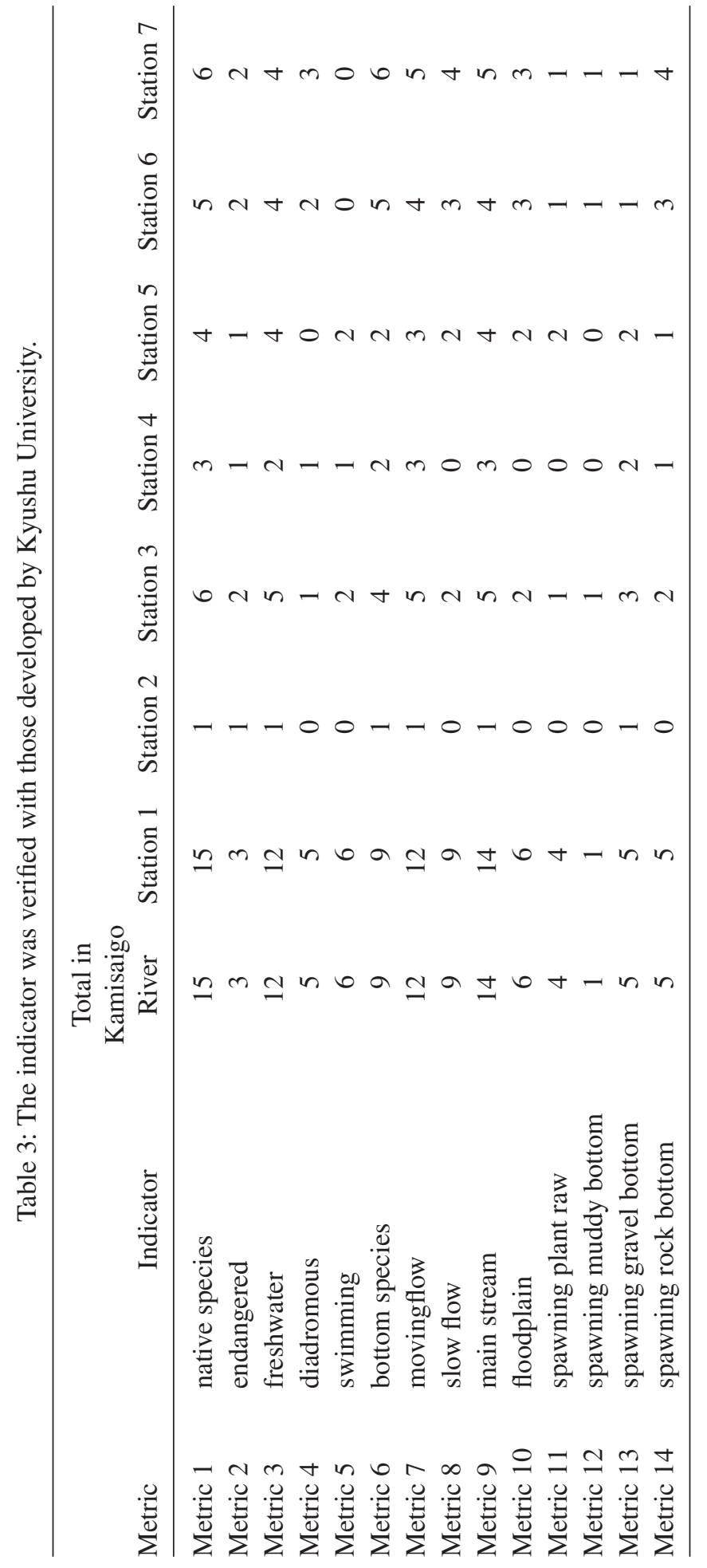




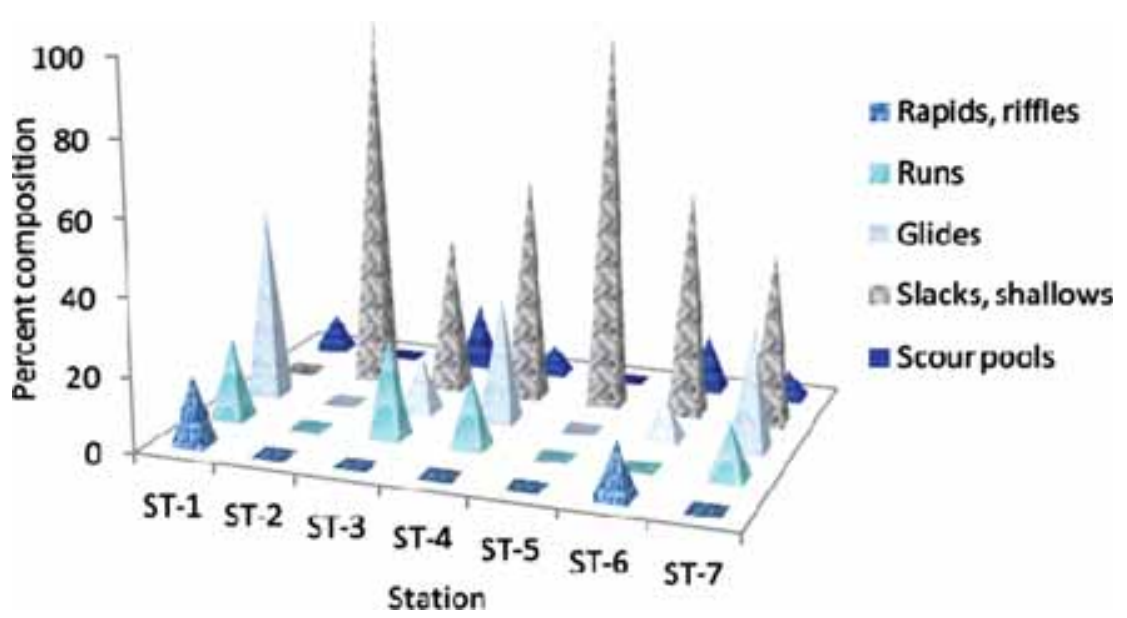

Figure 4: Composition of the flow ecology in the Kamisaigo River.

Station 1. This station consisted predominantly (91\%) of fast-current shallow habitats (2 riffles/ rapids, 4 runs, 6 glides) and very few slow-current habitats (pools) about $16 \mathrm{~cm}$ in mean depth. Some vegetation occurred in approximately $90 \%$ of the channel. We found 15 species at this station: Anguilla japonica (3 individuals), Carassius auratus langsdorfii (2), Zacco platypus (109), Zacco temmincki (32), Rhinogobius sp. CB (95), Rhinogobius sp. OR (4), Cyprinus carpio (3), Rhinogobius giurinus (11), and one each of Phoxinus oxycephalus, Pseudogobio esocinus, Cobitis matsubarae, Carassius auratus buergeri, Misgurnus anguillicaudatus, Odontobutis obscura, and Gymnogobius petschiliensis. This station was considered to be in good condition, as all metrics exceeded the average values (Fig. 5), with the exception of metrics 2 (exotic species) and 16 (species that spawn in bivalves).

Station 2. This station consisted entirely of slow-current shallow habitats (slacks or shallows) with uniform conditions (Fig. 4). Overhanging vegetation, root wads, and aquatic vegetation were absent. Cobitis matsubarae (31 individuals) was the only species present at this site. As a result, the index scores for station 2 were low, and it was considered to be in poor condition.

Station 3. This station comprised $42 \%$ fast-current shallow habitats ( 3 runs, 1 glide), $42 \%$ slacks or shallows, and $16 \%$ scour pools of $20 \mathrm{~cm}$ depth. Some vegetation was present. We found five fish species: Zacco platypus (24 individuals), Zacco temmincki (2), Misgurnus anguillicaudatus (3), Cobitis matsubarae (4), and Rhinogobius sp. CB (1). This station was assessed as being in moderate condition, as nearly all of the metrics were similar to the average values. Metrics 13 and 14 (spawning on muddy bottoms and on gravel bottoms, respectively) slightly exceed the average values.

Station 4. This station comprised 49\% slow-current shallow habitats (scour pools of $18 \mathrm{~cm}$ depth and slacks/shallows) and 51\% fast-current shallow habitats (2 runs, 2 glides). Some vegetation occurred along approximately $20 \%$ of the channel. We observed three fish species: Zacco platypus (62 individuals), Rhinogobius sp. CB (5), and Cobitis matsubarae (4). This station was considered to be in poor condition, as all metrics were well below the average.

Station 5. This station was in similar condition to station 2 in that it consisted entirely of slowcurrent shallow habitats (slacks or shallows) in a very uniform condition; however, some vegetation 


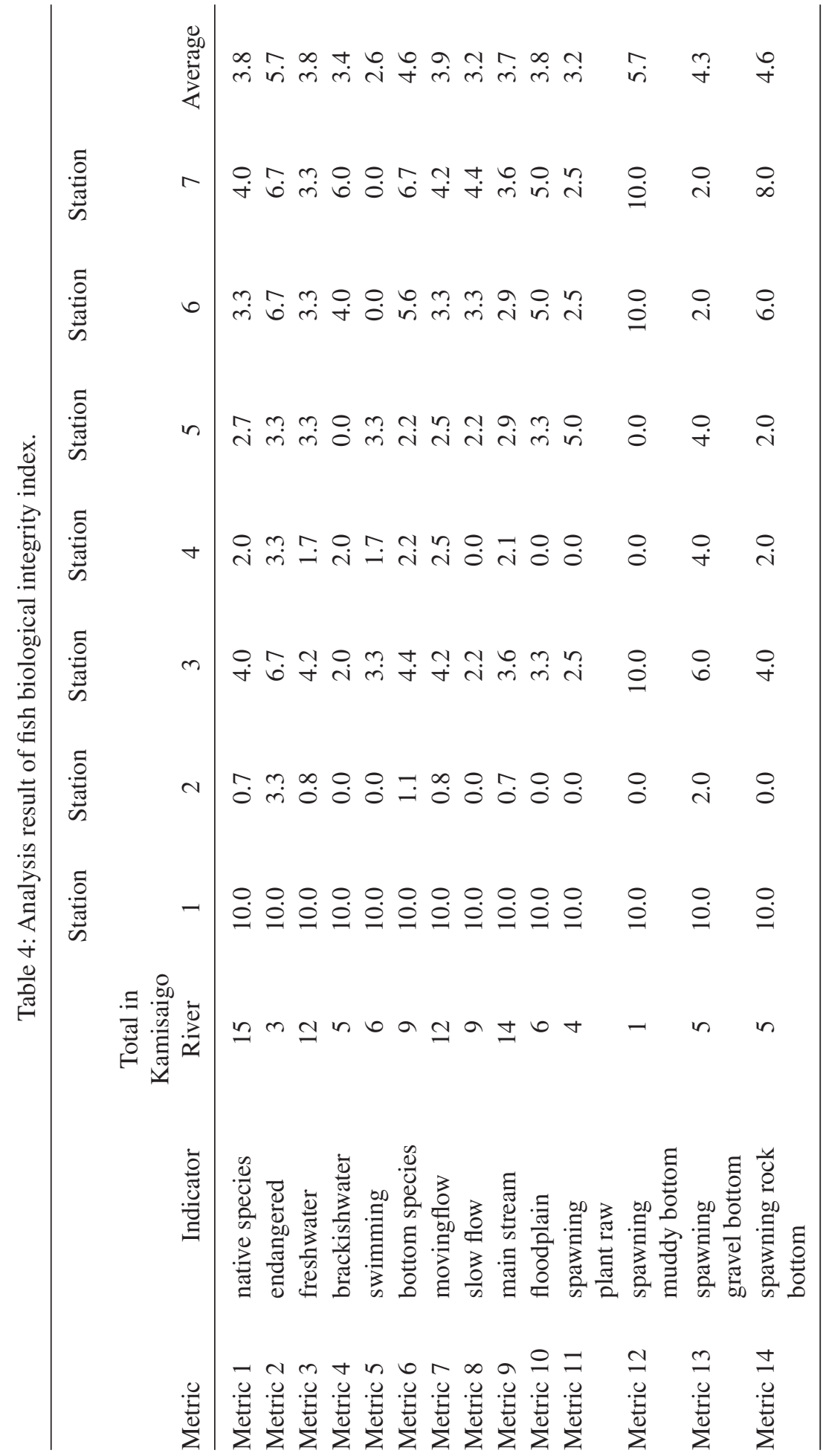



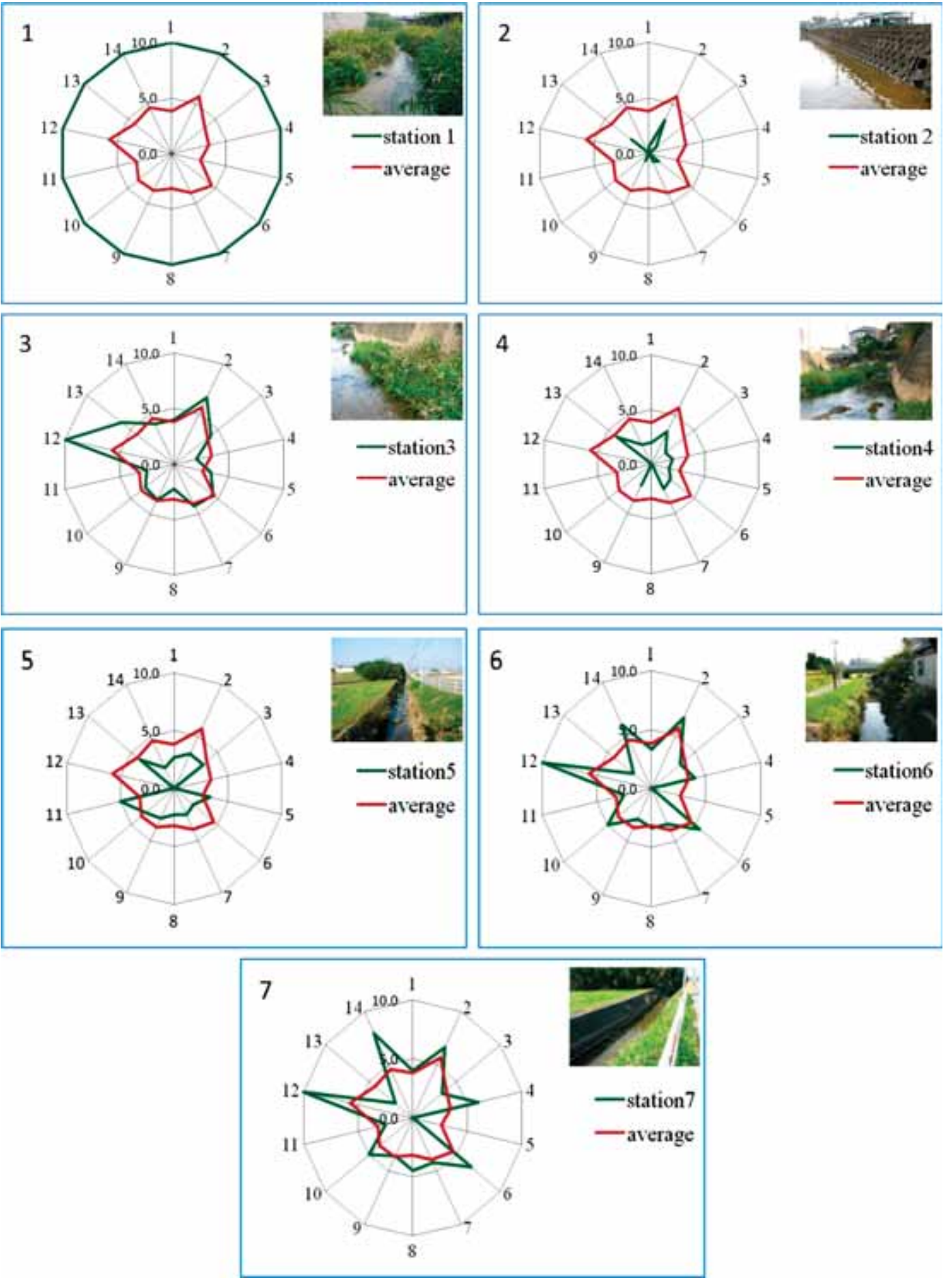

Figure 5: Fish biological health index. 
was present. We observed four fish species here: Cobitis matsubarae (28 individuals), Zacco platypus (11), Odontobutis obscura (4), and Cyprinus carpio (4). This station was assessed as being in poor condition, as nearly all of the metrics were slightly below the average. However, metric 12 (fish that spawn in vegetation) was slightly above the average.

Station 6. This station comprised 75\% slow-current shallow habitats (scour pools 19 and $35 \mathrm{~cm}$ deep and slacks/shallows) and 25\% fast-current shallow habitats ( 2 riffles/rapids, 1 glide). Vegetation was absent. We collected five fish species: Cobitis matsubarae (53 individuals), Rhinogobius sp. CB (34), Odontobutis obscura (27), Misgurnus anguillicaudatus (4), and Rhinogobius sp. OR (3). This station was considered to be in moderate condition because nearly all of the metrics were similar to the average values, although metrics 11 (floodplain species), 13 (spawning on muddy bottoms), and 15 (spawning on rocky bottoms) were well above the average.

Station 7. This station comprised 52\% slow-current shallow habitats (scour pools $19 \mathrm{~cm}$ deep, and slacks or shallows) and $48 \%$ fast-current shallow habitats (1 run, 1 glide). Some vegetation occurred in approximately $10 \%$ of the channel. We found six fish species: Cobitis matsubarae (151 individuals), Odontobutis obscura (5), Rhinogobius sp. OR (3), and one individual each of Rhinogobius sp. CB, Misgurnus anguillicaudatus, and Gymnogobius petschiliensis. This station was considered to be in moderate condition, as nearly all metrics had values similar to the average, with the exceptions of metrics 5 (brackish water species), 13 (spawning on muddy bottoms), and 15 (spawning on rocky bottoms), which were clearly above the average.

In characterizing the stations in our study reach, we tried to follow the Japanese process for restoration planning. With awareness of rivers and lakes as invaluable natural resources, the Ministry of Construction has been working on establishing river control methods which emphasize conservation of the natural environment. Amendment of the River Environment Law and enactment of the Environmental Assessment Law in 1997 emphasized the need for river works to achieve natural diversity, high biodiversity, and aesthetic landscapes [1]. However, technology that supports river improvement in harmony with the natural environment has not developed sufficiently, because it requires interdisciplinary research based on civil engineering and ecology.

At our study site, the Fukutsu City Government incorporated our ideas for restoration. Reconstruction of the Kamisaigo River took place in stages according to the availability of funds and prioritization of the rehabilitation process that we proposed. Reconstruction began at station 4 , followed by stations 2 and 3. Below we discuss the restoration approaches that considered the physical environment and the conservation of fish habitat.

Station 2 was restored by re-meandering of the river. The wavelength at the meander was assumed to be about $120 \mathrm{~m}$, which would allow a more natural river flow. The roadside river bank was improved by the addition of a porous revetment in front of the hard bank (rap stone method). Porous banks provide good habitat [1]. The opposite bank was improved by removal of the concrete revetment and sodding of the bank to prevent erosion (Fig. 6A, B). Natural stones placed in the stream reproduced riffles (Fig. 6C).

Station 3 was restored by a porous revetment on the right bank and vegetation cover on the left bank (Fig. 7).

Station 4 was restored to enhance stream naturalness and environmental functions. The concrete revetment was removed, doubling the stream width. The stream was connected to the riparian zone via a sloped river bank (Fig. 8), restoring the ecotone and continuity between land and water. Flow conditions were varied by the placement of $1-\mathrm{m}$ rocks (Fig. 8). The moderate bank slope invites visitors down to the water [1].

Such a restoration program could also reduce fine sediment deposition in spawning and rearing habitats and provide spawning vegetation and recruitment gravel within the stream. 

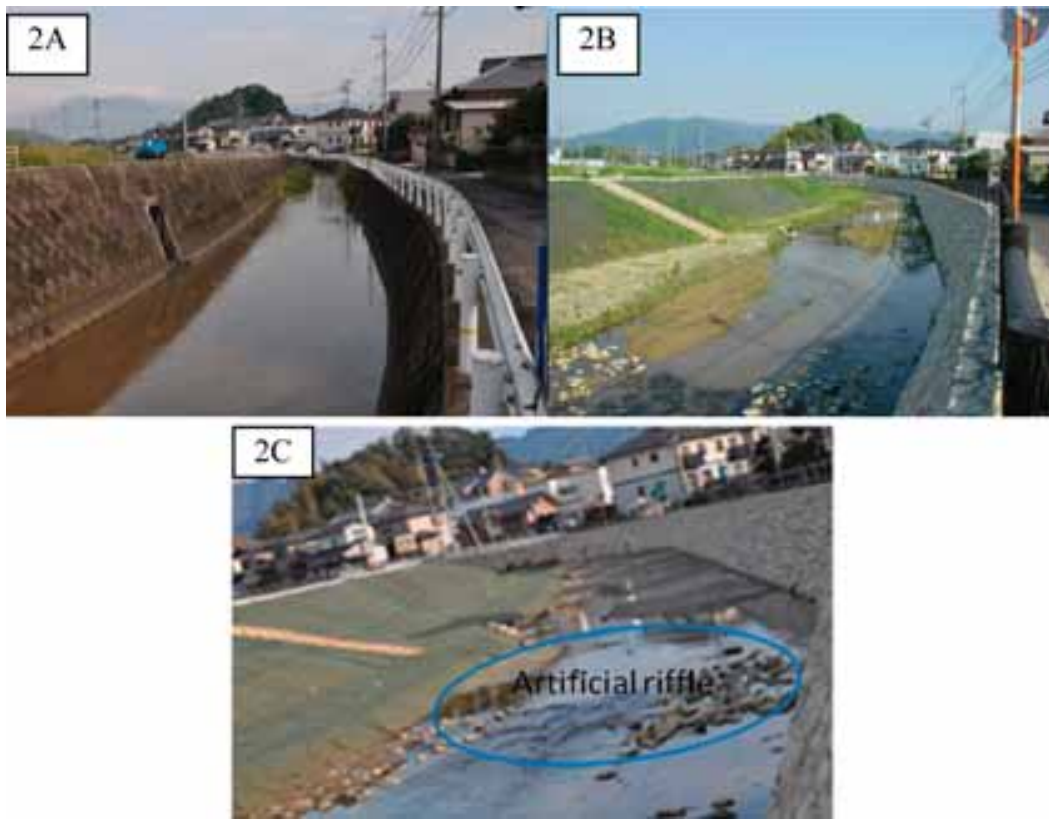

Figure 6: Station 2 condition. (A) Before restoration: a straight river lined with concrete. (B) Improvement of hydro-morphological status by re-meandering of the river and improvement of the river banks. (C) Two months after restoration; installation of artificial riffle.

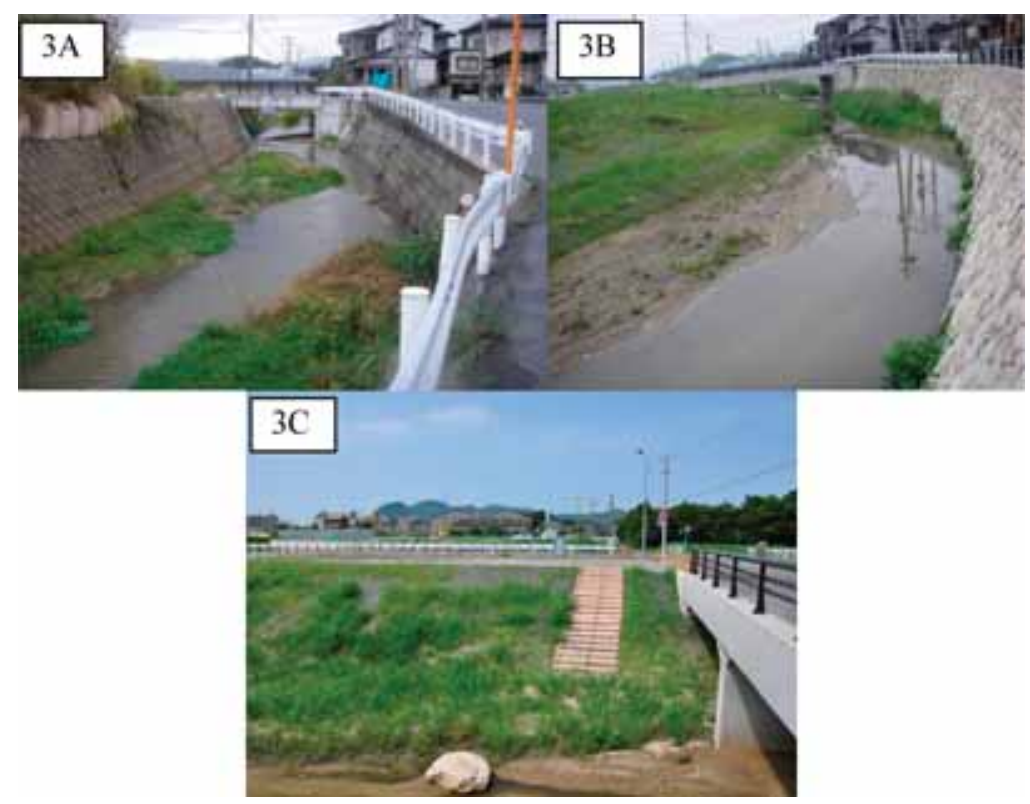

Figure 7: Station 3 condition. (A) Before restoration: concrete banks isolate the movement of organisms. (B, C) Three months after restoration: floodplain restored. 


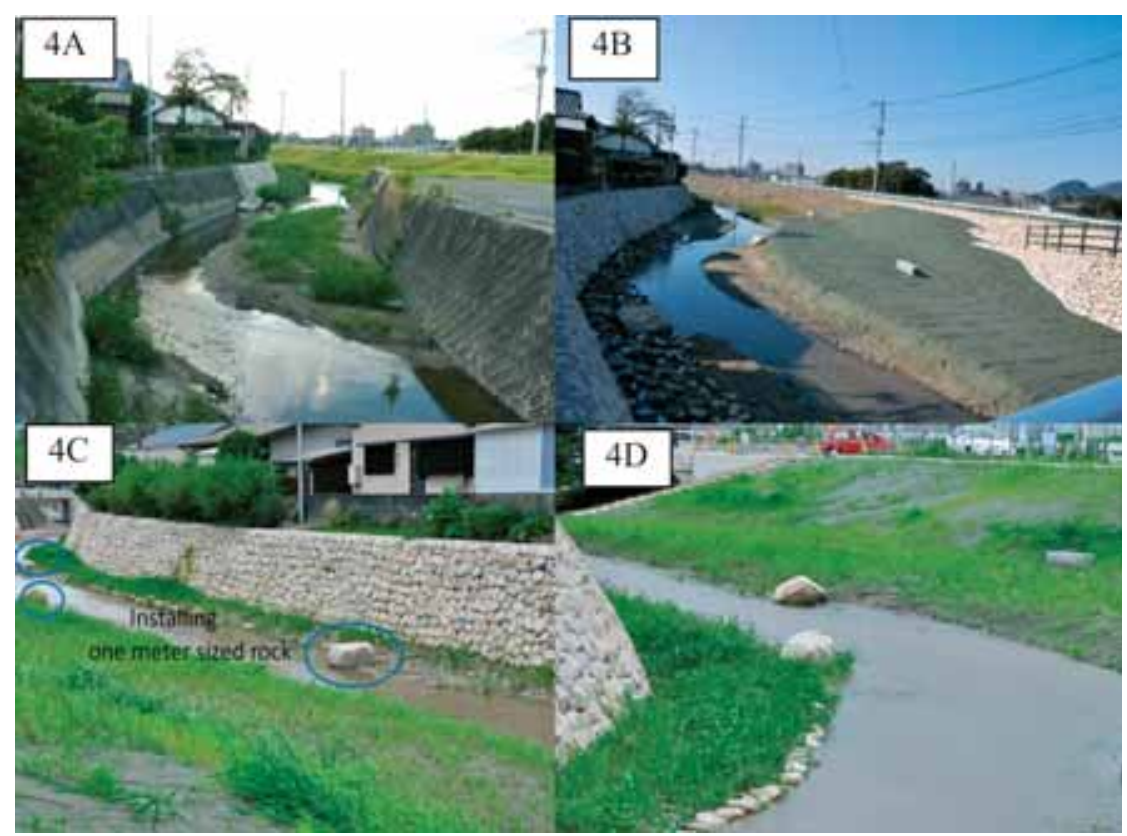

Figure 8: Station 4 condition. (A) Before restoration: the banks were lined by concrete. (B) Two months after restoration: revetments removed and river width doubled. (C) Installation of 1-m boulders. (D) Moderate bank slope.

\section{CONCLUSION}

Station 1 was in much better condition than the other six stations, as the area around it exhibited a diversity of habitat types. Stations 3, 6, and 7 were in moderate condition, with low values on at least one indicator. Stations 2, 4, and 5 were all in poor condition. This assessment will allow us to determine which indicators are particularly weak at specific locations throughout the river. Our results support the value of the fish biological integrity index for making preliminary diagnoses of ecological quality, thus aiding restoration efforts and the setting of priorities. The index can also be used to maximize the protection of endangered species. Thus, through the use of this index and the characterization of the flow ecology, restoration and improvement programs can be established at the exact locations where spawning and rearing habitats are required.

\section{ACKNOWLEDGMENTS}

This work was presented at the May 2011 water resources management conference in California, USA. The authors wish to thank the sponsors and organizers of the meeting, most particularly the Wessex Institute of Technology, UK; an anonymous reviewer; and constructive comments from WIT Press Journals. This work was supported by a grant from the Japan Bank International Corporation, by the Watershed Management Laboratory, Department of Urban and Environmental Engineering, Kyushu University, and by the Global Centers of Excellence (GCOE) program. It was also partly supported by the Research Institute of East Asia Environments, Kyushu University. 


\section{REFERENCES}

[1] Shimatani, Y., Conservation and Restoration of River Environment: Practice of Nature-abundant River Restoration, Kajima Publishing: Tokyo, 2000.

[2] The U.S. Environmental Protection Agency (EPA), Recommended Determination of the U.S. Environmental Protection Agency Region III Pursuant to Section 404@ on the Clean Water Act Concerning the Spruce No.1 Mine Logan County, West Virginia, 2008.

[3] Karr, J.R. \& Dudley, D.R., Draft: What is Biological Integrity, 2002.

[4] Shimatani, Y., Ecological Health; Evaluation and Restoration of River Ecosystems, Japan, 2000.

[5] Nakajima, J., Shimatani, Y., Itsukushima, R., \& Onikura, N., Assessing riverine environments for biological integrity on the basis of ecological features of fish. Advanced in River Engineering, 16, pp. 449-454, 2010.

[6] Karr, J.R., Rivers as sentinels: using the biology of rivers to guide landscape management. In: R.J. Naiman \& R.E. Bilby, eds, The Ecology and Management of Stream and Rivers in the Pacific Northwest Coastal Ecoregion, Springer-Verlag: New York, 1996.

[7] Itsukushima, R., Shimatani, Y., Nakajima, J., Kawaguchi, Y., Segment-based eco-regions based on fish fauna as a biological indicator. Journal of Hydroscience and Hydraulic Engineering, 2010 . 